\title{
Learning System, Job Competency, and Curriculum of College of Beauty and NCS-based Learning
}

\author{
Young-Rae Kim, Eun-Jun Park \\ Department of Hair and Makeup Design, Seokyeong University, Seoul, Korea
}

*Corresponding author: Eun-Jun Park, Department of Beauty Arts, Seokyeong University, 124 Seogyeong-ro, Seongbuk-gu, Seoul 02713, Korea Tel.: +82 29407853

Email: ayamdream@hanmail.net

Received June 8, 2017

Revised August 30, 2017

Accepted September 18, 2017

Published December 30, 2017

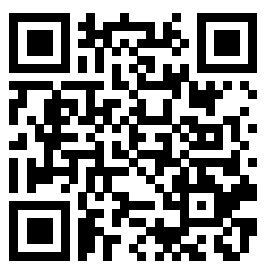

\begin{abstract}
Purpose: This study aims to investigate the learning system of National Competency Standards (NCS)-based learning in the beauty department, which focuses on practical education, and to examine the effects of the learning system on job competency and the curriculum in order to provide effective NCS education information and academic data. Methods: The data collected through questionnaires for 211 beauty department students in the Seoul and Gyeonggi areas were analyzed using Statistical Package for the Social Sciences (SPSS) 22.0. Results: The results showed that the NCS learning system had significant effects on job competency, and the learning system had significant effects on the curriculum. Therefore, the learning system is an important variable affecting job competency and curriculum. Conclusion: The following are the implications of this study. First, the fear of employment should be eliminated and field learning should be naturally linked to employment. Second, to enhance the effectiveness of NCS-based curriculum management, it is necessary to differentiate the curriculum, which requires practice rather than a theoretical curriculum.
\end{abstract}

Keywords: Department of beauty, NCS, Learning system, Job competency, Curriculum

\section{Introduction}

산업현장에서 요구되는 능력개발을 위해 정부에서는 과정 평가형 자격 제도, 일학습병행 자격 제도 등을 도입하고 있 다. 이와 더불어 고등직업교육기관인 대학교에서는 특성화 전 문대학 육성사업의 일환으로 대학교의 경쟁력 제고를 위해 국 가직무능력표준(National Competency Standards, NCS) 기반 직업 교육과정 도입을 추진하고 있다(Lee \& Park, 2016). NCS는 현장성을 강화하고 산업현장의 직무수행을 위 하여 필요한 지식 - 기술 - 소양 개발, 핵심 역량으로서의 직 업기초능력 개발, 학습자의 진로개발 역량과 생애 학습능력 증진을 목적으로 하고 있으며(Lee, 2016), 2014년 도입 이후 교육과정 개발 및 교재개발, 전공 관련 시설 및 설비 확보 등 에 꾸준한 노력을 기울이고 있다(Ham et al., 2016).

$\mathrm{NCS}$ 는 기존의 이론중심 수업 방식에서 벗어나 산업계 수 요를 반영한 실무 능력 중심 수업으로의 전환이라는 큰 변화 를 요구한다. 특히 실무과목의 경우 2016년부터 NCS 학습모
듈을 수업에서 활용할 것을 권고하고 있어(Hahm \& Park, 2015), 전문교과 교사들과 학생들이 새로운 수업 실행과 관련 해서 가지는 관심은 매우 클 것으로 예상된다.

$\mathrm{NCS}$ 에 관련된 선행연구를 살펴보면 Joo \& Kim (2016)은 전문대학 학생들에게 직접 적용하여 NCS 직업기초능력 증 진을 위한 프로그램을 개발하였고, Son (2016)은 NCS 적용 교과목과 미적용 교과목에 대한 만족도를 비교하여 NCS 적 용 교과목의 만족도가 더 크다는 결론을 도출해 냈으며, $\mathrm{Oh}$ (2016)는 NCS 기반 교과목에 대한 학습자 만족에 대해 연구 하여 NCS 기반 교과목의 만족도가 높다는 결론과 함께 학습 자 만족을 제고시키기 위한 방안으로 교수자의 사전준비와 피 드백을 제시하였다.

이렇듯 NCS 기반 교육은 활발히 연구되고 있는 실정이며 안정화 되기 위해 시행착오를 겪는 과정 속에 있다. 개인의 경력개발과 국가차원의 인적 자원 개발이 체계적으로 이루어 지도록 하기 위하여 NCS 과정 연구는 계속 이루어져야 하며 교육과정과 직무능력에 대한 연구가 필요하다고 사료된다. 특 
히 미용학과는 현장성을 중요시 여기는 대표적인 전공과목으 로 교과목의 대부분이 실무 중심으로 이루어져 있으나(Jung \& Park, 2017; Kim \& Kim, 2015), 취업 후에 다시 재교육 을 받아야만 하는 경우가 많고, 학교에서 배운 직무능력이 산 업현장의 수요와 일치하지 않는 현상이 발생하고 있어 NCS
기반 교육의 필요성이 더욱 요구되고 있다. 그러나 미용학과 학생들의 $\mathrm{NCS}$ 기반 교육에 대한 연구는 미비한 실정이다. 따 라서 미용학과의 NCS 학습체계에 대해 파악하여 이를 지원 하고 향상시킬 수 있는 방안 마련이 절실한 상황이다.

이에 본 연구에서는 실무교육이 중점적으로 이루어지는 미

Table 1. Configuration of a questionnaire

\begin{tabular}{lll}
\hline Research variables & Scale (No. of questions) & Quotation \& applied data \\
\hline General characteristics & Nominal scale (6) & Organization of researchers \\
Learning system & 5-point Likert scale (17) & Ham et al. (2016), Kim (2016), Kwon \& Cha (2016), Lee (2016) \\
Job competency & 5-point Likert scale (10) & Kang \& Jeon (2015), Kim et al. (2015a), Lee \& Lee (2015) \\
Curriculum & 5-point Likert scale (15) & Kim et al. (2016), Lee \& Han (2016), Ryu \& Ryu (2016) \\
\hline
\end{tabular}

Table 2. General characteristics

\begin{tabular}{|c|c|c|c|}
\hline Item & & Frequency $(\mathrm{N})$ & Percentage (\%) \\
\hline \multirow{2}{*}{ Gender } & Men & 74 & 35.0 \\
\hline & Women & 137 & 65.0 \\
\hline \multirow{3}{*}{ Educational institution } & College & 132 & 62.5 \\
\hline & University & 70 & 33.2 \\
\hline & Lifelong education center & 9 & 4.3 \\
\hline \multirow{5}{*}{ Major } & Hair & 125 & 59.2 \\
\hline & Makeup & 42 & 19.9 \\
\hline & Skin & 28 & 13.3 \\
\hline & Nail art & 10 & 4.7 \\
\hline & Etc. & 6 & 2.8 \\
\hline \multirow{8}{*}{ Reasons for choosing major } & Aptitude & 110 & 52.1 \\
\hline & Advice from parents and acquaintances & 29 & 13.7 \\
\hline & Advice from school or institute teacher & 7 & 3.3 \\
\hline & High employment rate & 12 & 5.7 \\
\hline & Founded in & 9 & 4.3 \\
\hline & It looks nice & 2 & 0.9 \\
\hline & To learn skills & 28 & 13.3 \\
\hline & Etc. & 14 & 6.6 \\
\hline \multirow{6}{*}{$\begin{array}{l}\text { The most important factors in } \\
\text { beauty education }\end{array}$} & Practical skills & 78 & 37.0 \\
\hline & Professional theory knowledge & 21 & 10.0 \\
\hline & Service, personality education & 49 & 23.2 \\
\hline & Ability to adapt to the beauty scene & 34 & 16.1 \\
\hline & Creativity & 12 & 5.7 \\
\hline & Pride and commitment to beauty & 17 & 8.1 \\
\hline \multirow{5}{*}{ Appropriate educator education } & High school graduation & 7 & 3.3 \\
\hline & College graduation & 47 & 22.3 \\
\hline & University graduation & 78 & 37.0 \\
\hline & Graduate school graduation & 18 & 8.5 \\
\hline & Does not matter & 61 & 28.9 \\
\hline Total & & 211 & 100.0 \\
\hline
\end{tabular}


용학과를 대상으로 하여 $\mathrm{NCS}$ 기반 학습의 학습체계를 알아 보고자 하였으며, 학습체계가 직무능력과 교육과정에 어떠한 영향을 미치는지 살펴봄으로써 효과적인 NCS 교육에 대한 정보와 학문적 자료를 제공하는데 그 목적이 있다.

\section{Methods}

\section{1. 연구대상 및 자료수집}

본 연구의 조사대상은 서울과 경기도 지역의 전문대학, 대 학교, 평생교육원 미용학과 학생을 대상으로 설정하였다. 자 료의 수집방법으로 자기기입식 설문지법이 사용되었으며, 예 비조사와 본 조사를 통해 연구문제를 해결하는데 필요한 자료 가 수집되었다. 2017년 3월 1일부터 3월 15 일까지 총 20부의 예비조사를 통해 측정도구인 설문지의 구성과 내용을 수정 및
보완한 후 본 조사를 실시하였다. 본 조사는 2016년 3월 16일 부터 2016년 3월 30일까지 실시되었고 총 230부의 설문지를 배포하여 수거된 220 부의 설문지 중 분석에 사용되기 불충분 하다고 판단되는 9 부의 설문지를 제외한 211 부가 최종 분석 자료로 사용되었다.

\section{2. 측정항목 및 내용}

본 연구는 자료의 수집을 위해 설문지법이 사용되었다. 설 문 문항은 크게 일반적 특성, 학습체계, 직무능력, 교육과정 의 48문항으로 이루어졌으며, 명목척도와 리커트 척도로 구 성되었다. 본 연구에 사용된 모든 리커트 척도는 ' 1 :전혀 그렇 지 않다'에서 '5:매우 그렇다'까지의 5 점 리커트 척도가 사용 되었다. 설문지의 구체적인 내용은 Table 1 과 같다.

Table 3. Validity and reliability of learning system

\begin{tabular}{|c|c|c|c|c|}
\hline \multirow[b]{2}{*}{ Questions } & Variable 1 & Variable 2 & Variable 3 & \multirow[b]{2}{*}{ Commonality } \\
\hline & $\begin{array}{l}\text { Education } \\
\text { system }\end{array}$ & $\begin{array}{l}\text { Practice } \\
\text { equipment }\end{array}$ & $\begin{array}{l}\text { Learning } \\
\text { module }\end{array}$ & \\
\hline $\begin{array}{l}\text { There are many opportunities for field trips and experiences } \\
\text { through NCS courses }\end{array}$ & 0.854 & 0.080 & 0.232 & 0.789 \\
\hline $\begin{array}{l}\text { There are many opportunities for internships in the industry } \\
\text { through NCS courses }\end{array}$ & 0.842 & 0.064 & 0.197 & 0.752 \\
\hline $\begin{array}{l}\text { Through the NCS curriculum, industrial field practice is helpful } \\
\text { for actual employment }\end{array}$ & 0.763 & 0.115 & 0.376 & 0.737 \\
\hline $\begin{array}{l}\text { Through the NCS curriculum, on-the-job training takes into } \\
\text { consideration the characteristics of each major }\end{array}$ & 0.746 & 0.165 & 0.352 & 0.707 \\
\hline $\begin{array}{l}\text { The NCS curriculum provides many courses closely related to } \\
\text { industry practice }\end{array}$ & 0.741 & 0.207 & 0.341 & 0.708 \\
\hline $\begin{array}{l}\text { Through an NCS-based curriculum, a student can expect } \\
\text { standardization of universities }\end{array}$ & 0.580 & 0.299 & 0.213 & 0.471 \\
\hline Training time configured in the NCS module is appropriate & 0.538 & 0.295 & 0.293 & 0.463 \\
\hline NCS practice materials are fully utilized in class & 0.138 & 0.869 & 0.258 & 0.841 \\
\hline NCS lab equipment is fully stocked & 0.199 & 0.851 & 0.148 & 0.785 \\
\hline The NCS lab supplies the latest equipment & 0.242 & 0.849 & 0.161 & 0.805 \\
\hline NCS lab materials are working well & 0.064 & 0.836 & 0.281 & 0.783 \\
\hline There are a variety of NCS lab materials & 0.144 & 0.833 & 0.165 & 0.741 \\
\hline $\begin{array}{l}\text { Learning using the NCS module was conducted according to } \\
\text { the lecture plan }\end{array}$ & 0.303 & 0.247 & 0.754 & 0.721 \\
\hline $\begin{array}{l}\text { Knowledge of the major was improved by the class that } \\
\text { applied the NCS learning module }\end{array}$ & 0.322 & 0.163 & 0.740 & 0.678 \\
\hline $\begin{array}{l}\text { I think I got enough basic knowledge through the class that } \\
\text { applied the NCS learning module }\end{array}$ & 0.335 & 0.248 & 0.735 & 0.714 \\
\hline Practical skills have been improved by using the NCS module & 0.393 & 0.212 & 0.705 & 0.697 \\
\hline $\begin{array}{l}\text { The lesson with the NCS module clearly showed the goal and } \\
\text { contents }\end{array}$ & 0.324 & 0.332 & 0.651 & 0.639 \\
\hline Eigen value & 4.460 & 4.167 & 3.402 & \\
\hline Description variant (\%) & 26.235 & 24.511 & 20.015 & \\
\hline Cumulative variance (\%) & 26.235 & 50.746 & 70.761 & \\
\hline Cronbach's $\alpha$ & 0.908 & 0.933 & 0.886 & \\
\hline Bartlett's unit matrix $=4560.106(\mathrm{df}=136 ;$ Sig. $=0.000), \mathrm{KMO}=0$ & & & & \\
\hline
\end{tabular}

$\mathrm{df}$, degree of freedom; Sig, significance; KMO, Kaise-Mayer-Olkin. 
Table 4. Validity and reliability of job competency

\begin{tabular}{|c|c|c|c|}
\hline \multirow{2}{*}{ Question } & Variable 1 & Variable 2 & \multirow{2}{*}{ Commonality } \\
\hline & Job fitness & Job utilization & \\
\hline The curriculum provides enough practical understanding & 0.851 & 0.251 & 0.787 \\
\hline The ability to understand the theory is sufficient through the curriculum & 0.824 & 0.241 & 0.738 \\
\hline There is enough job analysis capability through the curriculum & 0.794 & 0.287 & 0.713 \\
\hline The curriculum has enough capacity to demand industrial sites & 0.792 & 0.323 & 0.732 \\
\hline Self-development skills are sufficient through the curriculum & 0.787 & 0.265 & 0.690 \\
\hline It helped me to develop my career in the future & 0.218 & 0.859 & 0.785 \\
\hline It helped to develop a basic vocational ability & 0.279 & 0.852 & 0.804 \\
\hline It helped me acquire beauty skills & 0.254 & 0.816 & 0.730 \\
\hline It helped me get a certificate & 0.270 & 0.723 & 0.596 \\
\hline Information on the completion of major courses was well received & 0.331 & 0.705 & 0.607 \\
\hline $\begin{array}{l}\text { Eigen value } \\
\text { Description variant (\%) } \\
\text { Cumulative variance (\%) } \\
\text { Cronbach's } \alpha\end{array}$ & $\begin{array}{r}3.654 \\
36.538 \\
35.538 \\
0.907\end{array}$ & $\begin{array}{r}3.529 \\
35.292 \\
71.829 \\
0.889\end{array}$ & \\
\hline Bartlett's unit matrix=2359.229 (df=45; Sig. $=0.000), \mathrm{KMO}=0.906$. & & & \\
\hline
\end{tabular}

df, degree of freedom; Sig, significance; KMO, Kaise-Mayer-Olkin.

Table 5. Validity and reliability of curriculum

\begin{tabular}{|c|c|c|c|c|}
\hline \multirow[b]{2}{*}{ Questions } & Variable 1 & Variable 2 & Variable 3 & \multirow[b]{2}{*}{ Commonality } \\
\hline & $\begin{array}{l}\text { Quality of } \\
\text { education }\end{array}$ & $\begin{array}{l}\text { Educational } \\
\text { awareness }\end{array}$ & Education link & \\
\hline The curriculum is systematically structured & 0.838 & 0.136 & 0.132 & 0.738 \\
\hline Course time allocation is appropriate & 0.834 & 0.150 & 0.192 & 0.756 \\
\hline Evaluation method is appropriate & 0.804 & 0.203 & 0.184 & 0.721 \\
\hline Ratio of theoretical and practical classes is appropriate & 0.765 & 0.158 & 0.261 & 0.679 \\
\hline $\begin{array}{l}\text { It is appropriate for the curriculum to be operated by the } \\
\text { professor }\end{array}$ & 0.684 & 0.246 & 0.370 & 0.666 \\
\hline It consists of subjects that meet the major & 0.677 & 0.255 & 0.207 & 0.566 \\
\hline $\begin{array}{l}\text { I am aware of NCS-based education contents and } \\
\text { instructional goals }\end{array}$ & 0.234 & 0.846 & 0.241 & 0.839 \\
\hline $\begin{array}{l}\text { I understand the difference between an NCS-based } \\
\text { curriculum and a general curriculum }\end{array}$ & 0.225 & 0.827 & 0.224 & 0.784 \\
\hline I am aware of the NCS-based curriculum & 0.158 & 0.818 & 0.170 & 0.722 \\
\hline $\begin{array}{l}\text { I am aware of the integration of NCS } \\
\text { work+learning+qualifications }\end{array}$ & 0.168 & 0.805 & 0.290 & 0.761 \\
\hline $\begin{array}{l}\text { The developed NCS module is different from the existing } \\
\text { learning materials }\end{array}$ & 0.233 & 0.750 & 0.316 & 0.717 \\
\hline $\begin{array}{l}\text { The module includes practical training required in the } \\
\text { industry after graduation }\end{array}$ & 0.209 & 0.235 & 0.774 & 0.698 \\
\hline Curriculum theory and practical contents are linked & 0.304 & 0.296 & 0.761 & 0.758 \\
\hline Contents of the curriculum can be utilized at the beauty site & 0.332 & 0.245 & 0.734 & 0.709 \\
\hline $\begin{array}{l}\text { This course is for the basic theory of subjects and for the } \\
\text { basic practice certification exam }\end{array}$ & 0.188 & 0.315 & 0.665 & 0.577 \\
\hline Eigen value & 4.051 & 3.815 & 2.816 & \\
\hline Description variant (\%) & 27.004 & 25.431 & 18.773 & \\
\hline Cumulative variance (\%) & 27.004 & 52.434 & 71.207 & \\
\hline Cronbach's $\alpha$ & 0.903 & 0.920 & 0.843 & \\
\hline Bartlett's unit matrix $=3590.029(\mathrm{df}=105 ;$ Sig. $=0.000), \mathrm{KMO}$ & & & & \\
\hline
\end{tabular}

df, degree of freedom; Sig, significance; KMO, Kaise-Mayer-Olkin. 


\section{3. 분석방법}

수집한 자료를 분석하여 연구문제를 검정하기 위해 SPSS 22.0 (IBM, USA)이 사용되었고, 자료의 분석방법은 연구문 제에 맞게 순차적으로 적용되었으며 다음과 같다. 첫째, 조 사대상의 일반적 특성을 알아보기 위해 빈도분석을 하였다. 둘째, 학습체계, 직무능력, 교육과정의 차원을 알아보기 위 해 요인분석과 신뢰도분석을 하였으며 요인적재값은 0.40 이 상을 기준으로 하였고, 신뢰도 값은 0.50 이하이면 변수로 서 받아들일 수 없는 것으로 보았다. 요인의 추출방법으로 주 성분분석법이 사용되었고, 요인의 회전방법으로는 베리맥스 (varimax)가 사용되었다. 셋째, 학습체계가 직무능력에 미치
는 영향을 알아보기 위해 다중회귀분석을 실시하였다. 넷째, 학습체계가 교육과정에 미치는 영향을 알아보기 위해 다중회 귀분석을 실시하였다. 독립변수의 투입방법으로 입력 방법이 사용되었으며, 유의구간은 0.05 이하이다.

\section{Results and Discussion}

\section{1. 조사대상의 일반적 특성}

조사대상의 일반적 사항을 알아보기 위해 빈도분석을 실시 한 결과는 Table 2 와 같다. 성별은 남자 $35.0 \%$, 여자 $65.0 \%$

Table 6. Influence of the learning system on the job competency

\begin{tabular}{|c|c|c|c|c|c|c|}
\hline Dependent variables & Independent variables & B & SE B & $\beta$ & $t$ & $p$ \\
\hline \multirow{4}{*}{ Job fitness } & (a constant) & -0.030 & 0.052 & & -0.582 & 0.561 \\
\hline & Education system & 0.338 & 0.049 & 0.411 & $6.858^{* * *}$ & 0.000 \\
\hline & Practice equipment & 0.214 & 0.050 & 0.256 & $4.249^{* * *}$ & 0.000 \\
\hline & Learning module & 0.269 & 0.055 & 0.290 & $4.871^{* * *}$ & 0.000 \\
\hline \multirow{4}{*}{ Job utilization } & (a constant) & 0.001 & 0.057 & & 0.023 & 0.982 \\
\hline & Education system & 0.514 & 0.055 & 0.517 & $9.416^{* * *}$ & 0.000 \\
\hline & Practice equipment & 0.111 & 0.056 & 0.110 & $1.987^{*}$ & 0.048 \\
\hline & Learning module & 0.409 & 0.061 & 0.363 & $6.666^{* * *}$ & 0.000 \\
\hline
\end{tabular}

$p<0.05 ;{ }^{* * *} p<0.001$.

Job fitness: modified $\mathrm{R}^{2}=0.264 ; F=26.138 ; p=0.000$.

Job utilization: modified $\mathrm{R}^{2}=0.382 ; F=44.238 ; p=0.000$.

$\mathrm{B}$, unstandardized coefficient; SE B, standard error B; $\beta$, standardized coefficient; $t$, $t$-value; $p$, probability of significance; Modified $\mathrm{R}^{2}$, modified correlation coefficient; $F, F$-value.

Table 7. Influence of the learning system on the curriculum

\begin{tabular}{|c|c|c|c|c|c|c|}
\hline Dependent variables & Independent variables & B & SE B & $\beta$ & $t$ & $p$ \\
\hline \multirow{4}{*}{ Quality of education } & (a constant) & -0.025 & 0.060 & & -0.414 & 0.679 \\
\hline & Education system & 0.462 & 0.057 & 0.457 & $8.073^{* * *}$ & 0.000 \\
\hline & Practice equipment & 0.108 & 0.059 & 0.105 & 1.844 & 0.067 \\
\hline & Learning module & 0.443 & 0.064 & 0.387 & $6.891^{* * *}$ & 0.000 \\
\hline \multirow{4}{*}{ Educational awareness } & (a constant) & 0.087 & 0.058 & & 1.493 & 0.137 \\
\hline & Education system & 0.272 & 0.055 & 0.324 & $4.933^{* * *}$ & 0.000 \\
\hline & Practice equipment & 0.049 & 0.057 & 0.058 & 0.874 & 0.383 \\
\hline & Learning module & 0.149 & 0.062 & 0.156 & $2.398^{*}$ & 0.017 \\
\hline \multirow{3}{*}{ Education link } & (a constant) & 0.030 & 0.063 & & 0.466 & 0.642 \\
\hline & Education system & 0.232 & 0.060 & 0.252 & $3.838^{* * *}$ & 0.000 \\
\hline & Learning module & 0.252 & 0.068 & 0.242 & $3.710^{* * *}$ & 0.000 \\
\hline
\end{tabular}

${ }^{*} p<0.05 ;{ }^{* * *} p<0.001$

Quality of education: modified $\mathrm{R}^{2}=0.342 ; F=37.411 ; p=0.000$.

Educational awareness: modified $\mathrm{R}^{2}=0.114 ; F=10.007 ; p=0.000$.

Education link: modified $\mathrm{R}^{2}=0.115 ; F=10.083 ; p=0.000$.

$\mathrm{B}$, unstandardized coefficient; SE B, standard error B; $\beta$, standardized coefficient; $t$, $t$-value; $p$, probability of significance; Modified $\mathrm{R}^{2}$, modified correlation coefficient; $F, F$-value. 
로 여자가 높게 나타났고, 교육기관은 전문대학 $62.5 \%$, 대학 교 $33.2 \%$, 평생교육원 $4.3 \%$ 로 전문대학이 가장 높게 나타났 다. 전공은 헤어 $59.2 \%$, 메이크업 $19.9 \%$, 피부 $13.3 \%$, 네일 아트 $4.7 \%$, 기타 $2.8 \%$ 로 헤어가 가장 높게 나타났으며, 전 공 선택 이유로는 적성에 맞아서 $52.1 \%$, 부모님이나 지인 권 유 $13.7 \%$, 학교나 학원 선생님의 권유 $3.3 \%$, 취업이 잘될 것 같아서 $5.7 \%$, 창업이 쉬울 것 같아서 $4.3 \%$, 멋있어 보여 서 $0.9 \%$, 기술을 배우고 싶어서 $13.3 \%$, 기타 $6.6 \%$ 로 적성 에 맞아서가 가장 높게 나타났다. 미용교육 시 가장 중요한 요인을 알아본 결과 실기테크닉 $37.0 \%$, 전문적인 이론 지식 $10.0 \%$, 서비스 및 인성 교육 $23.2 \%$, 미용현장에 대한 적응 능력 $16.1 \%$, 창의성 $5.7 \%$, 미용인의 자긍심과 사명감 $8.1 \%$ 로 실기테크닉이 가장 높게 나타났으며, 적절한 교육자 학력으 로는 고등학교 졸업 $3.3 \%$, 전문대 졸업 $22.3 \%$, 대학교 졸업 $37.0 \%$, 대학원 졸업 $8.5 \%$, 상관없다 $28.9 \%$ 로 대학교 졸업이 가장 높게 나타났다.

\section{2. 학습체계, 직무능력, 교육과정의 타당성 및 신뢰도}

학습체계, 직무능력, 교육과정 문항에 대한 타당성 및 신 뢰도 검증을 위해 요인분석과 신뢰도 분석을 실시한 결과이 다. 학습체계는 Table 3 과 같이 교육체계, 실습장비, 학습모 듈의 세 개의 요인이 도출되었으며 전체 설명력은 약 $70.8 \%$, 신뢰도계수는 0.886 이상으로 나타났다. 직무능력은 Table 4 와 같이 직무적합도, 직무활용도의 두 개의 요인이 도출되었 으며 전체 설명력은 약 $71.8 \%$, 신뢰도계수는 0.889 이상으로 나타났다. 교육과정은 Table 5 와 같이 교육의 질, 교육인식, 교육연계의 세 개의 요인이 도출되었으며 전체설명력은 약 $71.2 \%$, 신뢰도계수는 0.843 이상으로 나타났다. 일반적으로 사용되는 고유값은 1.0 이상, 요인적재치와 공통성은 0.4 이 상으로 하고 각 요인을 구성하는 문항들을 토대로 하여 요인 을 명명하였다.

\section{3. 학습체계가 직무능력에 미치는 영향}

학습체계가 직무능력에 미치는 영향에 대한 회귀분석 결과 는 Table 6 과 같다. 직무적합도는 교육체계, 실습장비, 학습 모듈에서 유의미하게 영향을 미치는 것으로 나타났고 교육체 계, 실습장비, 학습모듈 변수가 직무적합도 요인을 예측하는 데 $26.4 \%$ 의 설명력을 갖는 것으로 나타났다. 독립변수의 영 향력을 살펴보면 교육체계 $(p<0.001)$, 실습장비 $(p<0.001)$, 학 습모듈 $(p<0.001)$ 변수가 유의미하게 정 $(+)$ 적으로 영향을 미 치는 것으로 나타났다. 이는 교육체계, 실습장비, 학습모듈 이 높아질수록 직무적합도도 높아지고 있음을 의미한다. 각 변수의 영향력을 살펴보면 교육체계( $\beta=0.411)$, 학습모듈( $\beta$ $=0.290)$, 실습장비 $(\beta=0.256)$ 순으로 크게 영향을 미치는 것
으로 나타났다.

직무활용도는 교육체계, 실습장비, 학습모듈에서 유의미하 게 영향을 미치는 것으로 나타났고 교육체계, 실습장비, 학습 모듈 변수가 직무활용도 요인을 예측하는데 $38.2 \%$ 의 설명력 을 갖는 것으로 나타났다. 독립변수의 영향력을 살펴보면 교 육체계 $(p<0.001)$, 실습장비 $(p<0.05)$, 학습모듈 $(p<0.001)$ 변 수가 유의미하게 정(+)적으로 영향을 미치는 것으로 나타났 다. 이는 교육체계, 실습장비, 학습모듈이 높아질수록 직무 활용도도 높아지고 있음을 의미한다. 각 변수의 영향력을 살 펴보면 교육체계( $\beta=0.517)$, 학습모듈 $(\beta=0.363)$, 실습장비( $\beta$ $=0.110)$ 순으로 크게 영향을 미치는 것으로 나타났다.

이 같은 결과는 NCS 기반 학습체계가 직무능력에 긍정적 인 영향을 미치고 있음을 나타내며 산업체 현장실습과 취업 에 실질적으로 도움이 되는 것을 보여주고 있다. Jeong et al. (2016)의 NCS 기반 교육과정과 비 NCS 기반 교육과정 의 취업효과 크기비교 연구에서 NCS 기반 교육과정을 수료 한 학생의 취업효과가 그렇지 않은 학생에 비해 높음을 밝혔 고, NCS 기반 학습이 직무능력에 미치는 영향력에 대해 언급 하였다. Yoo \& Kim (2016)의 연구에서는 지식, 기술, 능력을 잘 활용할수록 혁신적인 행동을 하게 되고 직무 적합성이 높 아진다고 나타나 본 연구 결과를 뒷받침 해주고 있다.

\section{4. 학습체계가 교육과정에 미치는 영향}

학습체계가 교육과정에 미치는 영향에 대한 회귀분석 결과 는 Table 7과 같다. 교육의 질은 교육체계, 학습모듈에서 유 의미하게 영향을 미치는 것으로 나타났고 교육체계, 학습모듈 변수가 교육의 질 요인을 예측하는데 $34.2 \%$ 의 설명력을 갖 는 것으로 나타났다. 독립변수의 영향력을 살펴보면 교육체 계( $p<0.001)$, 학습모듈 $(p<0.001)$ 변수가 유의미하게 정 $(+)$ 적 으로 영향을 미치는 것으로 나타났다. 이는 교육체계, 학습모 듈이 높아질수록 교육의 질도 높아지고 있음을 의미한다. 각 변수의 영향력을 살펴보면 교육체계( $\beta=0.457)$, 학습모듈 $(\beta$ $=0.387)$ 순으로 크게 영향을 미치는 것으로 나타났다. 실습 장비는 유의한 영향을 미치지 않았다.

교육인식은 교육체계, 학습모듈에서 유의미하게 영향을 미 치는 것으로 나타났고 교육체계, 학습모듈 변수가 교육인식 요인을 예측하는데 $11.4 \%$ 의 설명력을 갖는 것으로 나타났다. 독립변수의 영향력을 살펴보면 교육체계 $(p<0.001)$, 학습모듈 $(p<0.05)$ 변수가 유의미하게 정(+)적으로 영향을 미치는 것 으로 나타났다. 이는 교육체계, 학습모듈이 높아질수록 교육 인식도 높아지고 있음을 의미한다. 각 변수의 영향력을 살펴 보면 교육체계( $\beta=0.324)$, 학습모듈 $(\beta=0.156)$ 순으로 크게 영 향을 미치는 것으로 나타났다. 실습장비는 유의한 영향을 미 치지 않았다. 
교육연계는 교육체계, 실습장비, 학습모듈에서 유의미하게 영향을 미치는 것으로 나타났고 교육체계, 실습장비, 학습모 듈 변수가 교육연계 요인을 예측하는데 $11.5 \%$ 의 설명력을 갖 는 것으로 나타났다. 독립변수의 영향력을 살펴보면 교육체계 $(p<0.001)$, 실습장비 $(p<0.05)$, 학습모듈 $(p<0.001)$ 변수가 유 의미하게 정 $(+)$ 적으로 영향을 미치는 것으로 나타났다. 이는 교육체계, 실습장비, 학습모듈이 높아질수록 교육연계도 높 아지고 있음을 의미한다. 각 변수의 영향력을 살펴보면 교육 체계( $\beta=0.252)$, 학습모듈 $(\beta=0.242)$, 실습장비 $(\beta=0.149)$ 순 으로 크게 영향을 미치는 것으로 나타났다.

이 같은 결과는 NCS 기반 학습체계가 교육과정에 긍정적 인 영향을 미치고 있음을 나타내며 특히 교육의 질에 큰 영향 을 미치는 것을 알 수 있다. 또한 학생들은 실습장비보다는 교육체계나 학습모듈에 더욱 큰 비중을 두고 있음을 알 수 있 다. Yun \& Kim (2017)의 NCS 경쟁력 강화 방안 연구에서 $\mathrm{NCS}$ 기반 학습에 가장 중요한 요인으로 교육의 질을 꼽았고 Kim et al. (2015b)은 NCS 교육전문가의 역할로 산업체와의 교육연계를 중요한 요인으로 보아 본 연구결과와 유사하였다.

\section{$\overline{\text { Conclusion }}$}

본 연구는 대학교 미용학과 학생들의 NCS 학습체계가 직 무능력과 교육과정에 미치는 영향을 알아보는 것을 목적으로 하였다. 서울, 경기도 지역의 미용학과 학생들을 대상으로 설 문지법을 통해 수집된 자료 211부는 SPSS 22.0을 통해 분석 되었고 적용된 분석방법은 빈도분석, 요인분석, 신뢰도분석, 회귀분석이었다.

연구결과는 다음과 같았다. 첫째, 조사대상의 일반적 특성 을 알아보기 위해 빈도분석을 실시한 결과 성별은 여성이 높 았고, 교육기관은 전문대학이 가장 높게 나타났다. 전공은 헤 어가 가장 높게 나타났으며, 전공 선택 이유로는 적성에 맞아 서가 가장 높게 나타났다. 미용교육 시 가장 중요한 요인으로 는 실기테크닉이 가장 높게 나타났으며, 적절한 교육자 학력 으로는 대학교 졸업이 가장 높게 나타났다. 둘째, 학습체계, 직무능력, 교육과정을 요인분석 한 결과, 학습체계는 교육체 계, 실습장비, 학습모듈의 세 가지 요인이 도출되었고, 직무 능력은 직무적합도, 직무활용도의 두 가지 요인이 도출되었으 며, 교육과정은 교육의 질, 교육인식, 교육연계의 세 가지 요 인이 도출되었다. 셋째, 학습체계가 직무능력의 하위요인인 직무적합도와 직무활용도에 미치는 영향을 알아본 결과 모두 유의한 영향을 미치는 것으로 나타났다. 넷째, 학습체계가 교 육과정의 하위요인인 교육의 질, 교육인식, 교육연계에 미치 는 영향을 알아본 결과 부분적으로 유의한 영향을 미치는 것
으로 나타났다.

이렇듯 대학교 미용학과 학생들의 NCS 학습체계가 직무능 력과 교육과정에 유의한 영향을 미치는 중요한 변수임을 확인 하였으며 본 연구의 결과에 따른 시사점으로는 첫째, 현장학 습 경험을 늘려 취업이 수월할 수 있도록 해야 한다. 본 연구 결과에서 현장실습과 산업체 연계가 직무능력과 교육의 질에 가장 큰 영향을 미치는 것을 확인할 수 있었다. 이는 학생들 이 현장학습 경험을 원하고 있는 것으로 볼 수 있으며 동시에 취업에 대한 두려움을 없애고 싶어하는 것으로 사료된다. 현 장학습 경험을 늘려 자연스럽게 취업으로 연결될 수 있게 해 야 할 것이다. 둘째, 현장성 있는 학습모듈을 개발해야 한다. 학습모듈도 직무능력과 교육과정에 큰 영향을 미치는 것으로 나타났다. 현장 실무내용과 경험을 반영하여 수료 후 현장에 서 바로 적용할 수 있는 실질적 구성요소들로 이루어진 학습 모듈 개발이 필요하다. NCS 기반 교육과정 운영의 효과성을 제고하기 위해서는 이론 교과목 보다는 실습이 요구되는 교과 목 위주의 차별화 전략이 필요할 것이다.

본 연구에서는 일부 지역의 미용학과 학생들을 대상으로 표 본구성을 했으므로 연구 결과를 일반화시키는데 제한점을 가 질 수 있으나, 본 연구를 바탕으로 다양한 변수를 세분화하여 후속연구가 이루어지길 기대한다.

\section{References}

Hahm YS, Park HS. Teaching methodology and contents on ERP in the area of supply chain management practices based on NCS (National Competency Standards). Journal of Product Research, 33: 79-89, 2015.

Ham NH, Kim JJ, Yuh K. A study on the development and operation of a curriculum based on National Competency Standard (NCS): focus on the case of department of real estate and urban future at Hanyang Cyber University. The Journal of the Korea Contents Association, 16: 694-711, 2016.

Jeong SJ, Woo MH, Kang SJ. A meta-analysis on the employment effect sizes of vocational training courses applying National Competency Standards (NCS). The Journal of Vocational Education Research, 35: 51-74, 2016.

Joo HJ, Kim HW. PBL program development and application for improving NCS vocational basic abilities: focusing on the case of $\mathrm{S}$ Health University. Culture and Convergence, 38: 327-358, 2016. 
Jung EY, Park MY. Work experience and satisfaction among beauty graduates in foreign countries. Asian Journal of Beauty and Cosmetology, 15: 33-43, 2017.

Kang SJ, Jeon MA. Research on the current status of NCSbased job qualifications, and jobseekers' understanding on them. The Korean Journal of Technology Education, 15: 130-152, 2015.

Kim JR, Kim JW. Study on the development direction of establishing beauty qualifications job category based on the NCS and new qualifications framework. Jounal of the Korean Society of Cosmetology, 21: 1252-1261, 2015.

Kim JS. Effects of task analysis on learning outcomes in the NCS-based beauty sector: focusing on facial skin care subject. Journal of Investigative Cosmetology, 12: 175183, 2016.

Kim SJ, Kim JW, Kim JS. The recognition about the National Competency Standards based vocational curriculum from the teachers of industrial field specialized high school. The Korean Journal of Technology Education, 16: 167-190, 2016.

Kim Y, Song HD, Lee J. A Dephi study on the roles and competencies of NCS education professionals. The Korean Journal of Human Resource Development Quarterly, 17: 47-75, 2015b.

Kim YR, Choi SC, Lee TJ, Yun WY. A research on continuous quality improvement of NCS - based curriculum: in the case of department of tax accounting \& information in K College University. Tax Accounting Research, 46: 107131, $2015 a$.

Kwon SY, Cha SJ. A study of the major courses operation on National Competence Standards (NCS) at department of library and information science: focusing on educational experience of instructor. Journal of the Korean Biblia Society for Library and Information Science, 27: 129-149, 2016.
Lee KB, Lee SH. Qualitative study of development scale to rate expertise of hair designers by revised Delphi method. Jounal of the Korean Society of Cosmetology, 21: 414-427, 2015.

Lee S, Park HS. NCS course design and result analysis of class application. Journal of the Korea Society of Computer and Information, 21: 157-163, 2016.

Lee SJ. Analysis of educational needs of teaching competencies of specialized subject teachers according to the introduction of NCS-based curriculum. The Journal of Vocational Education Research, 35: 1-16, 2016.

Lee YH, Han KS. The influences of educational programs design using National Competency Standards on education results of the IT sector. The Society of Convergence Knowledge Transactions, 4: 25-30, 2016.

Oh M. Satisfaction of learners of a college about courses based NCS (National Competency Standards). The Journal of the Korea Contents Association, 16: 338349, 2016.

Ryu JR, Ryu IG. A study on the development of an accounting learning module based on NCS. Korean Computers and Accounting Review, 14: 85-105, 2016.

Son WI. A comparative study on educational satisfaction NCS course and non NCS course. Tax Accounting Research, 49: 79-93, 2016.

Yoo SH, Kim C. Study on the effects of the personenvironment fit on the innovative work behavior of NCS office administration job workers: focusing on the mediating effect of the fulfillment perception of the psychological contract. Journal of Secretarial Sciences, 25: 59-81, 2016.

Yun W, Kim J. How to raise the competitiveness of tax accounting departments in colleges utilizing NCS. Korean Accounting Journal, 26: 197-221, 2017. 


\section{국문초록}

\section{미용학과 NCS 기반 학습의 학습체계, 직무능력, 교육과정에 관한 연구}

김영래, 박은준

서경대학교 헤어메이크업디자인학과, 서울, 한국

목적: 본 연구는 실무교육이 중점적으로 이루어지는 미용학과의 National Competency Standards (NCS) 기반 학습의 학습체계를 알아보고자 하였으며, 학습체계가 직무능력과 교육과정에 어떠한 영향을 미치는지 살펴봄으로써 효과적인 NCS 교육에 대한 정보 와 학문적 자료를 제공하는 것을 목적으로 하였다. 방법: 서울, 경기도 지역의 전문대학, 대학교, 평생교육원 미용학과 학생을 대상 으로 설문지법을 통해 수집된 자료 211부는 Statistical Package for the Social Sciences (SPSS) 22.0을 통해 분석되었다. 결과: 연 구결과 NCS 학습체계가 직무능력에 유의미한 영향을 미치는 것으로 나타났고, 학습체계가 교육과정에 유의미한 영향을 미치는 것 으로 나타나 학습체계가 직무능력과 교육과정에 중요한 영향을 미치는 변수임을 확인하였다. 결론: 본 연구 결과에 따른 시사점으 로는 첫째, 취업에 대한 두려움을 없애고 현장학습이 자연스럽게 취업으로 연결될 수 있게 해야 할 것이다. 둘째, NCS 기반 교육과 정 운영의 효과성을 제고하기 위해서는 이론 교과목 보다는 실습이 요구되는 교과목 위주의 차별화 전략이 필요할 것이다.

핵심어: 미용학과, 국가직무능력표준, 학습체계, 직무능력, 교육과정

\section{참고문헌}

강석주, 전미애. NCS 기반 신 직업자격 현황과 NCS에 대한 취업준비생의 인식 탐색. 한국기술교육학회지, $15: 130-152$, 2015.

권선영, 차성종. 문헌정보학 전공에서의 국가직무능력표준(NCS)을 활용한 교과목 운영에 관한 연구. 한국비블리아학회지, 27 : 129-149, 2016.

김세중, 김종욱, 김진수. NCS 기반 직업교육과정에 대한 공업계열 특성화고등학교 교사의 인식. 한국기술교육학회지, $16:$ 167-190, 2016.

김연경, 송해덕, 이지현. 델파이 조사를 통한 국가직무능력표준(NCS) 교육전문가의 역할 및 역량 탐색. $H R D$ 연구, $17: 47-75$, 2015b.

김영락, 최수천, 이태정, 윤우영. NCS 기반 교육과정의 지속적교육품질개선(CQI)에 관한 연구: K대학 세무회계정보과를 중심 으로. 세무회계연구, 46: 107-131, 2015a.

김정숙. NCS 기반 미용분야 교육과정 과제분석이 학습결과에 미치는 영향: 피부미용 얼굴관리 교과목을 중심으로. 대한미용학 회지, 12: 175-183, 2016.

김종란, 김정원. NCS 및 새로운 자격체계에 기초한 이 - 미용 자격직종 발전방향 수립에 관한 연구. 한국미용학회지, $21:$ 1252-1261, 2015.

류장열, 류인규. NCS 기반 회계 학습모듈 개발에 관한 연구. 전산회계연구, 14: 85-105, 2016.

손원일. NCS 적용 교과목과 NCS 미적용 교과목에 대한 교육만족도 비교연구. 세무회계연구, 49: 79-93, 2016.

오만덕. 전문대학의 NCS 기반 교과목에 대한 학습자 만족. 한국콘텐츠학회논문지, 16: 338-349, 2016.

유승혜, 김철희. 개인-환경 적합성이 NCS사무행정 직무종사자의 혁신적 업무행동에 미치는 영향에 관한 연구. 비서학논총,

25: 59-81, 2016.

윤우영, 김지영. 국가직무능력표준(NCS)을 활용한 전문대학 세무 및 회계관련 학과의 경쟁력 강화 방안. 회계저널, 26: 197-221, 2017.

이기봉, 이상혁. 수정된 델파이 기법을 활용한 헤어미용사 전문성 평가척도 개발을 위한 질적 연구. 한국미용학회지, $21: 414-$ 
427, 2015.

이수정. NCS 기반 교육과정 도입에 따른 전문교과 교사의 수업역량에 대한 교육요구도 분석. 직업교육연구, 35: 1-16, 2016. 이순미, 박혜숙. NCS 교과목 개발 및 수업 적용 결과 분석. 한국컴퓨터정보학회논문지, 21: 157-163, 2016.

이용희, 한경석. IT분야의 NCS 기반 교육과정 설계가 교육성과에 미치는 영향. 융복합지식학회논문지, 4: 25-30, 2016.

정선정, 우미혜, 강석주. 국가직무능력표준(NCS) 기반 훈련과정의 취업 효과크기에 관한 메타분석. 직업교육연구, 35: 51-74, 2016.

정은영, 박미영. 뷰티 전공자의 해외취업 실태 및 만족도에 미치는 요인. 아시안뷰티화장품학술지, 15: 33-43, 2017.

주현재, 김현우. 전문대학에서의 NCS 직업기초능력 증진을 위한 교육프로그램 개발: S 보건대학교 사례를 중심으로. 문화와 융합, 38: 327-358, 2016.

함남혁, 김재준, 여옥경. 국가직무능력표준(NCS) 기반 교육과정 개발 및 운영에 관한 연구. 한국콘텐츠학회논문지, 16: 694711, 2016.

함용석, 박현성. NCS에 기반한 공급망관리 실무인력 양성을 위한 ERP교육 방안 및 내용. 상품학연구, 33: 79-89, 2015. 


\section{中文摘要}

\section{美容专业NCS基础的学习体系，职务能力，教育课程的研究}

金榮來，朴銀俊

西京大学发型化妆设计科，首尔，韩国

目的：美容专业注重实践教育，通过调查国家职务能力标准National Competency Standards（NCS）的基础学习体系, 探讨学习体系如何影响职务能力和教育课程, 为课程提供有效的NCS教育信息和学术资料。方法: 对首尔、京畿道地区的 专科大学、本科以及终生教育院的美容专业学生为对象, 通过问卷调查收集211份资料, 利用Statistical Package for the Social Sciences（SPSS）22.0分析其数据。结果：NCS学习体系对职务能力有显著影响, 同时对教育课程也具有显著影 响。因此学习体系是职务能力和教育课程的重要变量。结论: 通过研究, 第一, 消除就业恐惧, 自然连接实习与就业。 第二，为提高NCS基础教育课程管理的有效性，有必要提供实习课程为主的差别化战略，而不是理论课程。

关键词: 美容学科, 国家职务能力标准, 学习体系, 职务能力, 教育课程 